\title{
Asthmatic symptoms and volatile organic compounds, formaldehyde, and carbon dioxide in dwellings
}

\author{
D Norbäck, E Björnsson, C Janson, J Widström, G Boman
}

\begin{abstract}
Objectives-As a part of the worldwide European Community respiratory health survey, possible relations between symptoms of asthma, building characteristics, and indoor concentration of volatile organic compounds (VOCs) in dwellings were studied.
\end{abstract}

Methods-The study comprised 88 subjects, aged 20-45 years, from the general population in Uppsala, a mid-Swedish urban community, selected by stratified random sampling. Room temperature, air humidity, respirable dust, carbon dioxide $\left(\mathrm{CO}_{2}\right)$, VOCs, formaldehyde, and house dust mites were measured in the homes of the subjects. They underwent a structured interview, spirometry, peak expiratory flow (PEF) measurements at home, methacholine provocation test for bronchial hyperresponsiveness, and skin prick tests. In addition, serum concentration of eosinophilic cationic protein (S-ECP), blood eosinophil count, and total immunoglobulin E (S-IgE) were measured. Results-Symptoms related to asthma were more common in dwellings with house dust mites, and visible signs of dampness or microbial growth in the building. Significant relations were also found between nocturnal breathlessness and presence of wall to wall carpets, and indoor concentration of $\mathbf{C O}_{2}$, formaldehyde, and VOCs. The formaldehyde concentration exceeded the Swedish limit value for dwellings $\left(100 \mu \mathrm{g} / \mathrm{m}^{3}\right)$ in one building, and $\mathrm{CO}_{2}$ exceeded the recommended limit value of $1000 \mathrm{ppm}$ in $26 \%$ of the dwellings, showing insufficient outdoor air supply. Bronchial hyperresponsiveness was related to indoor concentration of limonene, the most prevalent terpene. Variability in PEF was related to two other terpenes; $a$-pinen and $\delta$-karen.

Conclusion-Our results suggest that indoor VOCs and formaldehyde may cause asthma-like symptoms. There is a need to increase the outdoor air supply in many dwellings, and wall to wall carpeting and dampness in the building should be avoided. Improved indoor environment can also be achieved by selecting building materials, building construction, and indoor activities on the principle that the emission of volatile organic compounds should be as low as reasonably achievable, to minimise symptoms related to asthma due to indoor air pollution.

(Occup Environ Med 1995;52:388-395)

Keywords: volatile organic compounds; terpenes; formaldehyde; asthma

During recent decades, concern has increased about possible health effects resulting from indoor air pollution. ${ }^{1}$ Asthma is the most common lung disease associated with indoor pollutants, ${ }^{2}$ and affects about $5 \%$ of the adult Swedish population. ${ }^{3}$ There have been reports of increased morbidity and mortality from asthma and allergies in several countries, ${ }^{4-6}$ and it has been suggested that this increase may be due to increased concentrations of indoor pollutants in modern buildings. ${ }^{4}$ As the population in the industrialised world spends about $65 \%$ of their lives in their homes, ${ }^{7}$ exposures in the home environment might have a profound impact on respiratory health.

Indoor air may contain many different air pollutants, including microorganisms, allergens from mites or furry animals, nitrogen oxides, and volatile organic compounds (VOCs). Symptoms related to asthma caused by exposure to nitrogen dioxide $\left(\mathrm{NO}_{2}\right)$ from gas cooking have been studied extensively in children. A meta-analysis of several studies concluded that gas cooking increased the long term exposure to $\mathrm{NO}_{2}$ by $30 \mu \mathrm{g} / \mathrm{m},{ }^{3}$ and this exposure results in a $20 \%$ increase in risk of lower respiratory tract illness. ${ }^{8}$ A relation between lower airway symptoms and type of fuel used for cooking and heating has also been found in adults in northern Italy. ${ }^{9}$ The type of heating system and fuels for cooking may, however, differ greatly between different countries. In Scandinavia, most cooking is done by electric stoves, and most heating is by means of water borne central heating.

Indoor air may contain different types of VOCs, emitted from various sources-for example, building materials, consumer products, and human activities. Rarely, asthma is caused by sensitisation to specific indoor VOCs. As an example, one case of asthma was recently described where the cause was indirect exposure to a biocide used in a floor cleaner. ${ }^{10}$ Formaldehyde is a reactive volatile compound that may induce airway irritation at low concentrations. Due to differences in measurement techniques, formaldehyde, obviously a volatile compound, is not included in the common definition of VOCs. Recent prevalence studies have shown 
correlations between symptoms of asthma and damp housing conditions. ${ }^{11-12}$ Dampness in buildings favours growth of microorganisms and house dust mites within the building. ${ }^{13}$ Another source of airborne indoor microorganisms is air humidifiers, which may in rare cases cause asthma. ${ }^{14}$ Besides the increased risk of microbial growth and mites, dampness in buildings may also increase the emission of VOCs, due to degradation of building material, or microbial activity. ${ }^{15}$ One example of the first is hydrolysis of phthalates in PVC floor material, where an emission of 2-ethyl-hexanol can be detected. ${ }^{15}$ By contrast, 1-octen-3-ol is emitted from the metabolism of microorganisms but not from building materials. ${ }^{15}$ Allergy to house dust mites is a well known cause of asthma related to buildings. ${ }^{16}$ Few studies are, however, available where relations between asthmatic symptoms and VOCs have been investigated.

Our aim was to study possible relations between symptoms and clinical signs related to asthma in the general adult population and exposure to volatile organic indoor pollutants in dwellings.

\section{Materials and methods \\ STUDY POPULATION}

The European Community respiratory health survey is a multicentre study on the prevalence of allergies and asthma found in 48 centres in 23 countries throughout the world. ${ }^{17}$ Each centre covers a source population of about 150000 inhabitants within a defined geographical and administrative area. Sweden contributes with data from three such areas, one being the municipality of Uppsala.

The source population was all subjects living in the community of Uppsala in 1990, a mid-Swedish urban commune with a total population of 160000 inhabitants. In December 1990, a screening questionnaire was mailed to a random sample of 3600 men and women, aged 20-44 years, selected from the population register of Uppsala. A random subsample of 600 of these 3600 subjects was further examined for signs of atopy and bronchial hyperresponsiveness at the department of lung medicine. Blood samples were obtained and all subjects were interviewed and examined by specially trained nurses. All subjects gave their informed consent.

The study population of our study consisted of two groups of subjects further selected from the subsample. The first group was all subjects $(n=74)$ who had reported at least one of the following symptoms in the screening questionnaire: attacks of asthma during the past 12 months, nocturnal breathlessness in the past 12 months, or current use of asthma medication. Also, 80 subjects who gave negative answers to all these three questions were randomly selected, without matching.

These 154 subjects were contacted by post and by phone, and were offered air monitoring of their dwelling. These field measurements were performed from October 1991 to April 1992, as were the clinical investigations.
The study was blinded, to the extent that information from the exposure measurements was not linked to the medical information, until the data collection was completed. The protocol of the study was approved by the Ethics Committee of the Medical Faculty of Uppsala University.

\section{ASSESSMENT OF EXPOSURE}

Room temperature, air humidity, VOCs, respirable dust, and carbon dioxide concentration $\left(\mathrm{CO}_{2}\right)$ were measured in the living room and the bedroom in the houses of all participants. In the bedroom, additional measurements of formaldehyde, and guanine from house dust mites were performed. Measurements in the living room were performed in the centre of the room, $1.0 \mathrm{~m}$ above the floor. Bedroom measurements were performed beside the pillow of the bed, at the same height above the floor as the pillow. The bedroom door was closed, and no subject stayed in the bedroom during the VOC, $\mathrm{CO}_{2}$, respirable dust, and formaldehyde measurements.

Room temperature and air humidity were recorded with an Assman psychrometer. Concentrations of respirable dust were measured by a direct reading instrument based on light scattering (Sibata P-5H2, Sibata Scientific Technology, Japan). The instrument was calibrated by the manufacturer to $0.3 \mu \mathrm{m}$ particles of stearic acid. Indoor $\mathrm{CO}_{2}$ concentration was measured by a direct reading infrared spectrometer (Rieken RI-411A, Rieken Keini, Japan), calibrated by standard gases containing known concentrations of $\mathrm{CO}_{2}$. The average $\mathrm{CO}_{2}$ concentration in the dwelling was calculated, by taking the average of 30 minutes registration in the bedroom and 30 minutes registration in the living room.

Indoor concentrations of formaldehyde were measured with glass fibre filters impregnated with 2,4-dinitro-phenylhydrazine. ${ }^{18}$ The air sampling rate was $0.25 \mathrm{l} / \mathrm{min}$ for two hours. The filters were analysed by liquid chromatography. Volatile organic compounds, other than formaldehyde, were measured both in the bedroom and the living room by sampling on charcoal sorbent tubes. ${ }^{19}$ The air sampling rate was $1 \mathrm{l} / \mathrm{min}$ for two hours. The charcoal tubes were desorbed with $1 \mathrm{ml}$ of carbon disulphide before analysis, which was performed within one week from the sampling day with a gas chromatograph equipped with a flame ionisation detector. Sixteen common solvents were identified and quantified by the external standard technique, by comparing the retention times on two different columns. When quantifying low boiling uncalibrated compounds (C3-C12) the response factor of $n$-decane was used; high boiling unknown compounds used the response factor of a mixture of high boiling hydrocarbons (dodecylbenzenes). The total concentration of the identified and unidentified VOCs expressed as $\mu \mathrm{g} / \mathrm{m}^{3}$ was calculated. ${ }^{19}$

Settled bedroom dust was collected by standardised vacuum cleaning of both the bed mattress and the bedroom floor, with the same vacuum cleaner in all homes (ELRAM 
HSS 09, ELRAM, Sweden). In each bedroom, a sampling time of one minute $/ \mathrm{m}^{2}$ (five seconds/foot ${ }^{2}$ ) was applied to both the floor and the mattress. Presence of house dust mites in collected dust was detected by the semiquantitative Acarex-test, ${ }^{20}$ which gives a score from $0-3$. It has been validated against a quantitative immunological test with monoclonal antibody against house dust mites. ${ }^{20}$ According to the suggestions of van der Brempt et $a l^{20}$ an ACAREX score of 0 or 1 was regarded as negative, and a score of 2 or 3 was regarded as positive for the presence of allergenic concentrations of house dust mites. The test is based on a reaction to guanine in fecal pellets from dust mites, and is therefore not specific for house dust mites. ${ }^{21}$ Throughout this text, however, a positive ACAREX score is considered to be evidence of house dust mites.

\section{ASSESSMENT OF SYMPTOMS AND PERSONAL}

\section{FACTORS}

The screening and interview questionnaire used in the European Community respiratory health survey was a modified version of the International Union against Tuberculosis and Lung Disease (IUATLD) questionnaire. ${ }^{22}{ }^{23}$ All questions were translated to Swedish and then back to English, to minimise translation bias. The recall period for airway symptoms was 12 months. The questionnaire also contained questions on the dwelling, social situation, education, and environmental exposures. Symptoms related to asthma were defined as reported in the interview to have had in the past 12 months: $(a)$ wheezing or whistling in the chest; or (b) at least one daytime attack of shortness of breath during exercise or at rest; (c) at least one wakeful night because of breathlessness or tightness in the chest.

In addition, information on age, sex, and smoking habits was collected from the screening and interview questionnaire. Current smoker was defined as a subject who reported current smoking in the interview, or had stopped smoking less than a year ago.

\section{Assessment of clinical signs}

Atopy-Skin prick tests were carried out in a standardised way, by means of lancets coated with allergen (Phazets, Pharmacia Diagnostics, Uppsala, Sweden). The following allergens were tested: Dermatophagoides pteronyssinus (house dust mite), cat, dog, birch, Cladosporium, olive, ragweed, mugwort, timothy, and Alternaria. Histamine was used as a positive control. As proposed by Dreborn, atopy was defined as a prick test reaction to at least one of the allergens, with a mean diameter of $3 \mathrm{~mm}$ or greater. ${ }^{24} \mathrm{~A}$ negative control was used, and its mean diameter was subtracted from that of the allergens.

\section{LUNG FUNCTION AND BRONCHIAL}

HYPERRESPONSIVENESS

Forced expiratory volume in one second $\left(\mathrm{FEV}_{1}\right)$ was measured with the Spiro Medics computerised dry rolling seal spirometer system 2130 (Sensor Medics, Anaheim, California, USA). The predicted value for each subject was calculated. ${ }^{25}$ Peak expiratory flow (PEF, best of three measurements) was recorded twice daily for one week with a Mini-Wright peak flow meter (Clement Clark, London). Peak flow variability was calculated by dividing the difference between the highest and the lowest daily PEF reading by the daily mean PEF value. The index used is the one suggested by Higgins et al, who found this way of measuring peak flow to be the most sensitive when comparing asthmatic and non-asthmatic subjects. ${ }^{26}$ This index has also been described in a subsequent paper by the same group. ${ }^{27}$ Methacholine challenge was performed by a MEFAR inhalation dosimeter (MEFAR, Brescia, Italy). ${ }^{28}$ Bronchial hyperresponsiveness was defined as a positive methacholine test-that is, a reduction in $\mathrm{FEV}_{1}$ by at least $20 \%$ with an accumulated dose of less than or equal to $2 \mathrm{mg}\left(\mathrm{PD}_{20}\right)$.

\section{BIOCHEMICAL MARKERS OF INFLAMMATION}

AND ALLERGY

From each volunteer, $35 \mathrm{ml}$ of venous blood was collected, just before the methacholine provocation test. The same investigation sequence was applied to all participants. Blood eosinophil counts were analysed on a Hemalog 2R (Technicon Chemicals Company, Tournai, Belgium) in blood ( $5 \mathrm{ml}$ ) supplemented with ethylene diamine tetraacetic acid (EDTA, $0.34 \mathrm{~mol} / \mathrm{l}$ ). The concentration of eosinophilic cationic protein (S-ECP) was measured by means of a double antibody radioimmunoassay (Pharmacia Diagnostics AB, Uppsala, Sweden). ${ }^{29}$ The coefficients of variation within and between assays are less than $11 \%$, and the detection limit is less than $2 \mu \mathrm{g} / 1$. The $20 \mathrm{ml}$ blood sample used to measure S-ECP was allowed to coagulate for 60 minutes at room temperature after sampling. After that it was centrifuged for 10 minutes, the serum was poured into a new tube and then centrifuged again for 10 minutes. The serum was collected thereafter and kept frozen at $-70^{\circ} \mathrm{C}$ until analysed. Also, serum from another $10 \mathrm{ml}$ of blood was collected, and analysed for total serum immunoglobulin E (S-IgE) by the Pharmacia CAP system (Pharmacia Diagnostics AB, Uppsala, Sweden).

\section{STATISTICAL METHODS}

An unpaired $t$ test was used to study relations between asthmatic symptoms and independent continuous variables that were roughly normally distributed (room temperature, air humidity, and carbon dioxide concentration). The Mann-Whitney U test was applied for the crude analysis of relations between symptoms and other exposures that were not normally distributed (VOCs, respirable dust, and formaldehyde). The $\chi^{2}$ test or Fisher's exact test, depending on the number in the cells, was used for analysis of the relation between binary dependent and independent variables, Kendal rank correlation test (Tau-beta) was used when testing correlation between clinical signs and measured environmental exposures. Multivariate statistical analysis was performed 
by multiple logistic regression with the SPIDA statistical package (the Statistical Laboratory, Macquarie University, Australia).$^{30}$ Logarithmic values of formaldehyde and VOCs were applied in the model. The collinearity diagnostics described in the SPIDA manual were applied, and adjusted odds ratios (ORs) with a $95 \%$ confidence interval $(95 \% \mathrm{CI})$ were calculated. Adjustments were made for potential confounders: age, sex, and current smoking. To reduce detected collinearity problems, the data on formaldehyde and VOCs were centred by subtracting the mean concentration from each person. In all statistical analyses, two tailed tests and a 5\% level of significance was applied.

\section{Results}

The total response rate in the initial self administered questionnaire survey was $87 \%$. In the second part, the response rate was $81 \%$ (figure). Of the 154 subjects chosen for this study, $26(17 \%)$ were excluded because of migration. They had either moved to another dwelling during the study period $(n=19)$, or were working or living outside the municipality of Uppsala during the field study period $(n=$ $7)$. The non-participants $(n=40)$ consisted of 14 subjects who did not come to the medical investigation, 12 who could not be contacted at their home address, and 14 refused to participate in the exposure measurements. The remaining 88 subjects (57\%) participated in the medical interview, had lived in the same dwelling during the study period, and gave their approval for the measurements in their home. The non-participants did not differ from the participants for age, reported symptoms, smoking, bronchial hyperresponsiveness, or atopy. From the 88 participants,

Uppsala municipality

Random sample sent postal questionnaire 3600

\section{6 men and women}

\section{Random sample interviewed,} examined, blood tests, prick tests, bronchial provocation 600

488 men and women
All who answered yes to three questions on asthma

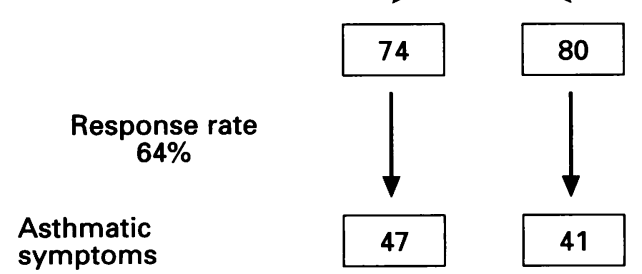

\section{Response rate} $81 \%$
The study population and response rates. information was obtained as follows: interview questionnaires from 88 subjects, spirometry in 82 , prick tests in 77 , methacholine challenge test in 73 , a peak flow diary in 68 , and blood samples from 74 subjects.

\section{PERSONAL CHARACTERISTICS}

Mean (SD) age of all participants was 32 (7) years, and the mean (range) duration in the present dwelling was six $(0.5-31)$ years. The mean (SD) $\mathrm{FEV}_{1}$ was $106 \%$ (13\%) of the predicted value, and the mean (range) variability in PEF was 5\% (1-18\%). Subjects with symptoms related to asthma had a higher prevalence of asthmatic medication, bronchial hyperresponsiveness, and were more often women. In contrast, the proportion of current smokers, and subjects with atopy, were similar among subjects with and without asthmatic symptoms (table 1). One of 17 people who had cats at home had a positive prick test to cat allergen. None of the seven subjects who had dogs were allergic to dog. Four subjects had a positive prick test to house dust mites (Dermatophagoides pteronyssinus). None of these had a positive ACAREX test for house dust mites in their home.

\section{CHARACTERISTICS OF BUILDINGS}

Most of the buildings were not situated near roads with heavy traffic, and about half the buildings (49\%) were built after 1970 (table 2). Half the buildings (51\%) were apartments in larger houses, and $49 \%$ were single family houses. Most of the buildings were heated by a water borne central heating system ( $87 \%)$, a few $(9 \%)$ were equipped with ducted air heating. The source of the heat was mainly hot water distributed by the commune through underground ducts $(73 \%)$, or electric radiators $(24 \%)$. In a few of the buildings, heat was produced by combustion of organic materials, mainly wood (25\%), and rarely central heating by oil $(5 \%)$ or kerosene heaters $(5 \%)$ were used. Some buildings had a combination of different heating systems. All buildings were equipped with electric stoves only, and none had a gas stove or any other type of gas heater. Indoor tobacco smoking was reported to occur in $23 \%$ of the homes, and was found during the measurements in four dwellings (5\%). Presence of wall to wall carpets was noticed in $18 \%$ of the dwellings,

Table 1 Prevalence of demographic and medical data for subjects with and without symptoms related to asthma $(n=88)$

\begin{tabular}{|c|c|c|}
\hline Characteristics & $\begin{array}{l}\text { Symptom } \dagger \\
(n=47) \\
(\%)\end{array}$ & $\begin{array}{l}\text { No symptom } \\
(n=41) \\
(\%)\end{array}$ \\
\hline Women & 72 & $32^{\star \star \star}$ \\
\hline Wheeze & 33 & $0^{\star \star \star}$ \\
\hline Day time breathlessness & 28 & $0^{\star \star \star}$ \\
\hline Nocturnal breathlessness & 25 & $0^{\star \star \star}$ \\
\hline Asthma medication & 30 & $0 \star \star \star \star$ \\
\hline Current tobacco smoker & 23 & 22 \\
\hline Atopy & 48 & 38 \\
\hline Bronchial hyperresponsiveness & 32 & $9 \star$ \\
\hline
\end{tabular}

No asthmatic symptoms
Random sample of those who answered no to thre questions on asthma

Response rate $57 \%$ 
Table 2 Characteristics of dwellings of subjects with and without symptoms related to asthma $(n=88)$

\begin{tabular}{|c|c|c|}
\hline Characteristics & $\begin{array}{l}\text { Symptom† } \\
(n=47)(\%)\end{array}$ & $\begin{array}{l}\text { No symptom } \\
(n=41)(\%)\end{array}$ \\
\hline \multicolumn{3}{|l|}{ Age of the dwelling: } \\
\hline$<1960$ & 32 & 17 \\
\hline $1961-70$ & 27 & 24 \\
\hline 1971-80 & 17 & 29 \\
\hline$>1980$ & 24 & 29 \\
\hline \multicolumn{3}{|l|}{ Type of house: } \\
\hline Detached & 32 & 29 \\
\hline Terrace & 15 & 22 \\
\hline Apartment & 49 & 53 \\
\hline Tobacco smoking indoors & 23 & 22 \\
\hline Cats or dogs at home & 28 & 24 \\
\hline Birds at home & 6 & 5 \\
\hline Presence of house dust mites $\ddagger$ & 21 & $5^{\star}$ \\
\hline Presence of wall to wall carpets $\ddagger$ & 19 & 17 \\
\hline Visible signs of dampness in the building $\neq$ & 23 & $7^{\star}$ \\
\hline \multicolumn{3}{|l|}{ Ventilation system: $\ddagger$} \\
\hline Natural ventilation only & 30 & 22 \\
\hline Mechanical exhaust air only & 32 & 41 \\
\hline Mechanical supply and exhaust air & 38 & 37 \\
\hline Dwelling situated near $(<50 \mathrm{~m})$ heavy traffic & 4 & 10 \\
\hline
\end{tabular}

${ }^{\star} \mathrm{P}<0.05$ by $\chi^{2}$ test; fas for table 1 ; fobserved or measured at inspection.

and $16 \%$ had visible signs of dampness in the building or microbial growth. Most of the houses had mechanical exhaust air ventilation, but $26 \%$ had natural ventilation only. Presence of house dust mites, defined as score 2 or 3 on the ACAREX test, was detected in $13 \%$ of the bedrooms (table 2 ).

SYMPTOMS RELATED TO ASTHMA IN RELATION TO CHARACTERISTICS OF THE BUILDINGS

Presence of house dust mites was significantly related to asthmatic symptoms: crude $\mathrm{OR}=$ $5 \cdot 3$ (95\% CI 1-2-22.8). A significant relation between visible signs of dampness in the building or microbial growth and asthmatic symptoms was also found: crude $O R=3.9$ $(95 \%$ CI $1 \cdot 1-14 \cdot 1)$. None of the other characteristics of the buildings differed significantly between subjects with and without asthmatic symptoms, when subjects who reported any type of asthmatic symptoms were compared with subjects without asthmatic symptoms (table 2). For nocturnal breathlessness, however, a significant relation was found for wall to wall carpets in the dwelling: crude $\mathrm{OR}=$

Table 3 Indoor concentration of selected volatile organic compounds (VOCs) $\left(\mu \mathrm{g} / \mathrm{m}^{3}\right)$ in dwellings of subjects with and without nocturnal attacks of breathlessness

\begin{tabular}{|c|c|c|}
\hline \multirow[b]{2}{*}{ Type of VOC } & \multicolumn{2}{|c|}{ Nocturnal breathlessness or chest tightness } \\
\hline & $\begin{array}{l}\text { Absence of }(n=62) \\
\text { mean (range) }\end{array}$ & $\begin{array}{l}\text { Presence of }(n=26) \\
\text { mean (range) }\end{array}$ \\
\hline 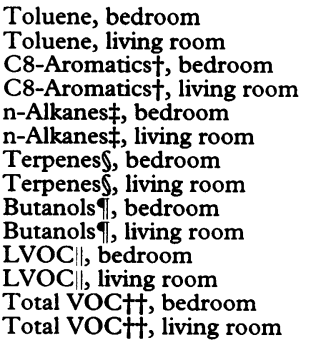 & $\begin{array}{l}21(3-230) \\
21(1-230) \\
23(4-190) \\
23(2-190) \\
19(2-150) \\
20(2-120) \\
52(5-350) \\
60(5-960) \\
10(<1-43) \\
10(<1-45) \\
99(9-2200) \\
130(9-1030) \\
310(70-2920) \\
300(70-1670)\end{array}$ & $\begin{array}{l}120(1-2330)^{\star \star} \\
120(3-2250)^{\star \star} \\
55(5-690)^{\star \star} \\
46(6-470)^{\star \star} \\
39(2-290)^{\star \star} \\
39(2-270)^{\star \star} \\
96(5-580)^{\star} \\
130(7-1010)^{\star} \\
19(1-90)^{\star} \\
18(2-84)^{\star} \\
370(21-5520)^{\star} \\
380(17-5010)^{\star \star} \\
790(90-9380)^{\star} \\
780(70-8350)^{\star \star}\end{array}$ \\
\hline
\end{tabular}

${ }^{\star} \mathrm{P}<0.05 ;{ }^{\star \star} \mathrm{P}<0.01$ by Mann-Whitney $U$ test.

† Sum of ethylbenzene, $m$-sylene, $\alpha$-xylene, and $p$-xylene.

$\$$ Sum of $n$-octane, $n$-nonane, $n$-decane, and $n$-undecane.

Sum of $a$-pinene, $\delta$-carene, and limonene.

TSum of $n$-butanol and iso-butanol.

Sum of unidentified compounds with a retention time below benzene.

t†Sum of all identified and unidentified compounds.
$4 \cdot 2(95 \%$ CI $1 \cdot 4-12 \cdot 3)$. The influence of carpeting was significant even after adjustment for possible influence of age, sex, current smoking, and other characteristics of the building by multiple logistic regression: adjusted $\mathrm{OR}=9 \cdot 7(95 \% \mathrm{CI} 2 \cdot 1-45 \cdot 3)$. No significant relation was found between nocturnal breathlessness and signs of dampness in the building or microbial growth. No significant relations were found between daytime attacks of shortness of breath and any characteristics of the buildings. Moreover, no significant relation was found between any type of symptoms related to asthma, and exposure to environmental tobacco smoke, or living near $(<50 \mathrm{~m})$ heavy traffic.

\section{SYMPTOMS RELATED TO ASTHMA AND}

MEASURED EXPOSURES

House dust mites were detected in $13 \%$ of the bedrooms, and a significant relation between presence of these and nocturnal breathlessness was found. The influence of dust mites was significant even after adjustment for possible influence of age, sex, current smoking, and other characteristics of the building: adjusted $\mathrm{OR}=8 \cdot 2 \quad(95 \%$ CI $1 \cdot 4-48 \cdot 1)$. Furthermore, the average concentration of $\mathrm{CO}_{2}$ was significantly higher in the homes of those people who reported nocturnal chest tightness, compared with subjects without such symptoms $(1020 \mathrm{ppm}$ and $850 \mathrm{ppm}$ respectively, $P<0.01)$. Also, a relation between formaldehyde concentration in the bedroom, and nocturnal symptoms was found $(P<0.01)$. The mean (range) concentration of formaldehyde was $29(<5-110) \mu \mathrm{g} / \mathrm{m}^{3}$ in homes of subjects with nocturnal breathlessness, compared with $17(<5-60) \mu \mathrm{g} / \mathrm{m}^{3}$ in homes of subjects without nocturnal breathlessness. The formaldehyde concentration exceeded the Swedish limit value for dwellings $\left(100 \mu \mathrm{g} / \mathrm{m}^{3}\right)$ in one building, but $\mathrm{CO}_{2}$ exceeded the recommended limit value of $1000 \mathrm{ppm}$ in $26 \%$ of the dwellings. For respirable dust concentration, no significant relation to nocturnal breathlessness could be shown. The room temperature (range 17.8$22.8^{\circ} \mathrm{C}$ ) and relative air humidity (range 33$75 \%$ ) was not significantly different in subjects with and without nocturnal symptoms.

In the initial analysis, a significant relation between any type of symptom related to asthma and concentration of total VOCs was found $(P<0.01)$. The relation between carpeting, $\mathrm{CO}_{2}$, formaldehyde, and total VOCs and asthmatic symptoms was most pronounced for nocturnal dyspnoea (table 3). Wheezing or whistling in the chest and daytime attacks of shortness of breath showed no significant relations to any measured exposures. Significant relations between nocturnal breathlessness and various subclasses of VOCs were also detected (table 3). The average concentrations of most compounds were similar in bedrooms and the living room, and a large proportion of the VOCs were low boiling VOCs that consisted of unidentified compounds with a boiling point lower than benzene (table 3 ). 
Table 4 Adjusted ORs (95\% CI) for nocturnal breathlessness in relation to $\mathrm{CO}_{2}$, formaldehyde ${ }^{\star}$, and significant types of VOCs ${ }^{\star}$

\begin{tabular}{lc}
\hline Type of compound & Adjusted OR $(95 \% \mathrm{CI})$ \\
\hline $\mathrm{CO}_{2} \dagger$ & $20 \cdot 0(2 \cdot 7-146)$ \\
Formaldehyde & $12 \cdot 5(2 \cdot 0-77.9)$ \\
Toluene & $4 \cdot 9(1 \cdot 1-22 \cdot 8)$ \\
C8-Aromatics & $6 \cdot 7(1 \cdot 0-45 \cdot 1)$ \\
Terpenes & $4 \cdot 0(1 \cdot 2-13.4)$ \\
LVOC & $4 \cdot 4(1 \cdot 3-15 \cdot 0)$ \\
TVOC & $9 \cdot 9(1 \cdot 7-58 \cdot 8)$ \\
\hline
\end{tabular}

${ }^{\star}$ Logarithmic values used in the regression models. Odds ratio calculated for a 10-fold increase of the indoor concentration adjusted for age, sex, current smoking, presence of wall to wall carpets, and presence of house dust mites.

tOdds ratio for an increase of the indoor concentration by $1000 \mathrm{ppm} \mathrm{CO}_{2}$ adjusted for age, sex, current smoking

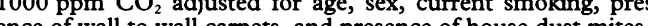
isum of ethylbenzene, $m$-xylene, $o$-xylene, and $p$-xylene.

$\ddagger$ Sum of ethylbenzene, $m$-xylene, $a$-xylene,
fSum of $a$-pinene, $\delta$-carene, and limonene.

SSum of $a$-pinene, $\delta$-carene, and limonene.
Sum of unidentified compounds with a retention time below benzene.

benzene.

"Sum of all identified and unidentified volatile organic compounds.

Some subclasses of VOCs were strongly related to each other and to total VOCs, particularly toluene, C8-aromates (xylene and ethylbenzene), $n$-alkanes, and low boiling VOCs. In contrast, butanols or terpenes were not significantly related to total VOCs. Significant relations between presence of house dust mites and the concentration of total VOCs, and some subclasses of VOCs, were also found. The total concentration of VOCs was $1050 \mu \mathrm{g} / \mathrm{m}^{3}$ in buildings that had house dust mites, and $350 \mu \mathrm{g} / \mathrm{m}^{3}$ in buildings without house dust mites $(P<0.05)$, but no relation was found between total VOCs and signs of microbial growth or dampness in the building. Carbon dioxide, a surrogate measure of the rate of air exchange, was related to total VOCs, but not related to formaldehyde or the presence of house dust mites. Formaldehyde concentration was higher in dwellings with wall to wall carpets $(\mathrm{P}<$ $0 \cdot 05)$, but no relation was found between carpeting and total VOCs.

To further evaluate the effect of formaldehyde and different VOCs statistical modelling by multiple logistic regression analysis was applied. Those seven classes of VOCs where the concentration in both the bedroom and the living room were significantly related to symptoms in the crude analysis were selected for further testing. The relations between nocturnal symptoms and $\mathrm{CO}_{2}$, formaldehyde, toluene, C8-aromates, terpenes, low boiling VOCs, and total VOCs were also significant in the logistic model (table 4). Due to collinearity between formaldehyde and volatile

Table 5 Correlation coefficientst between exposure to terpenes, and clinical signs of obstructive airway reactions

\begin{tabular}{|c|c|c|c|}
\hline Type of compound & $B H R \ddagger$ & $P E F S$ & $F E V_{1} \mathbb{9}$ \\
\hline $\begin{array}{l}\alpha \text {-Pinene, bedroom } \\
\alpha \text {-Pinene, living room } \\
\delta \text {-Karene, bedroom } \\
\delta \text {-Karene, living room } \\
\text { Limonene, bedroom } \\
\text { Limonene, living room }\end{array}$ & $\begin{array}{l}0.01 \\
0 \cdot 01 \\
0 \cdot 08 \\
0 \cdot 09 \\
0 \cdot 17^{\star} \\
0 \cdot 16^{\star}\end{array}$ & $\begin{array}{l}0 \cdot 26^{\star \star \star} \\
0 \cdot 21^{\star \star} \\
0 \cdot 18^{\star} \\
0 \cdot 19^{\star} \\
0 \cdot 08 \\
0 \cdot 12\end{array}$ & $\begin{array}{r}-0.05 \\
-0.05 \\
-0.01 \\
-0.03 \\
0.09 \\
0.07\end{array}$ \\
\hline
\end{tabular}

organic compounds, however, these exposures could not be kept in the models simultaneously. The effects of house dust mites and carpeting on nocturnal chest tightness were, however, significant even when the effects of formaldehyde and VOCs were controlled.

Finally, relations between clinical signs and indoor exposures were also investigated. No significant relations were found between bronchial hyperresponsiveness, variability in $\mathrm{PEF}, \mathrm{FEV}_{1} \%$, and presence of house dust mites, signs of dampness in the building, or microbial growth. For measured exposures, only compounds significantly related to nocturnal breathlessness in the logistic regression analysis were evaluated. Bronchial hyperresponsiveness was significantly related to the indoor concentration of limonene, the most prevalent terpene. Variability in PEF was related to the two other measured terpenes; $\alpha$-pinene and $\delta$-karen (table 5 ). On average, $64 \%$ of the terpenes consisted of limonene, $15 \%$ of $\delta$-karen, and $21 \%$ of $\alpha$-pinene. No activities known to emit terpenes, such as cleaning or peeling of citrus fruits, were observed during the measurements. No relations were found between bronchial hyperresponsiveness, variability in $\mathrm{PEF}, \mathrm{FEV}_{1} \%$, and the indoor concentration of formaldehyde, $n$-alkanes, aromatic compounds, or total VOCs. Furthermore, no significant relations were found between serum concentration of eosinophilic cationic protein, blood eosinophilic count, total serum immunoglobulin $\mathrm{E}$ concentration, and either carpeting, house dust mites, formaldehyde, or any of the VOCs significantly related to nocturnal breathlessness.

\section{Discussion and conclusion}

We have shown significant relations between asthmatic symptoms and dampness in the building, house dust mites, and indoor concentration of VOCs and formaldehyde. Also, significant relations between some clinical signs related to airway obstruction and the indoor concentration of terpenes were found.

The design was cross sectional and in such studies, selection effects may cause false negative results. This could be of particular significance for asthma, which is a severe condition. The failure to find a relation between pets and sensitisation is most probably due to health based selection that would cause sensitised subjects to avoid house pets. Moreover, the cross sectional design does not enable us to differentiate between exacerbation of symptoms in subjects with asthma, and induction of new asthma.

Many methodological problems of internal validity are inherent in an epidemiological study. In this particular study, selection bias due to low response rate is unlikely as the participation rate in the initial postal questionnaire was high (87\%). Also, the participants and non-participants in the clinical study did not differ in age, atopy, smoking habits, or airway symptoms. Response bias due to awareness of exposure may cause a general 
overreporting of symptoms in exposed groups. Also, a time difference between clinical investigations and exposure measurements may induce a possible bias. In our study, however, the exposure measurements were performed in parallel with the medical investigations, and could not influence the reporting of symptoms.

Despite the limitations of the cross sectional design and the study size, we could show significant relations between VOCs and symptoms related to asthma. A large number of statistical tests were made, but most of the relations were significantly below the $1 \%$ level, and similar results were obtained both in the crude analysis, and by logistic multiple regression analysis. Thus, we do not think that our conclusions are seriously biased by selection or response errors, or due to chance findings.

We found a relation between measured exposure and nocturnal symptoms, but not breathlessness during the daytime. One possible explanation could be that most people are not at home during the daytime, and if there is a cumulative effect of indoor pollutants at home it would be most likely to occur at the end of the night. Another explanation could be that the exposures are higher during the night than during the day, or that subjects are more susceptible to air pollutants during sleep. For practical reasons, our exposure measurements were performed during the day, without any subject in the bedroom. This enabled us to isolate the contribution of the building and its interior to the indoor concentrations of VOCs. During sleep however, human emissions are added to the background concentrations of VOCs, which could result in peak exposures higher than suggested by our measurements.

We found that the average indoor concentration of $\mathrm{CO}_{2}$ was above the comfort value of 1000 ppm in many dwellings in Sweden. This inadequate outdoor air supply leads to increased concentrations of volatile organic compounds, as well as other indoor pollutants. Either the rate of outdoor air supply, or the indoor concentration of carbon dioxide, are used as criteria of ventilation by most ventilation standards, ${ }^{31-32}$ and a comfort value of $1000 \mathrm{ppm}$ of $\mathrm{CO}_{2}$ has been adapted for work environments in Sweden. ${ }^{32}$ There is, however, sparse information in the scientific literature on the medical significance of poor outdoor air supply. Our result, however, has shown that nocturnal symptoms related to asthma are more common if the outdoor air supply is inadequate.

We showed a relation between asthmatic symptoms and signs of dampness in the building or microbial growth, which is in agreement with earlier observations. ${ }^{11-12} \mathrm{~A}$ relation between house dust mites and nocturnal asthmatic symptoms was also shown, even though most $(95 \%)$ of the subjects had a negative prick test to Dermatophagoides pteronyssinus. Moreover, none of the four subjects with that positive prick test had house dust mites in their home, which suggests that they had been sensitised in earlier dwellings. A possible explanation for our findings could be that the presence of house dust mites in dwellings is related to other indoor pollutants that trigger asthmatic symptoms.

Respiratory effects of exposure to nitrogen dioxide $\left(\mathrm{NO}_{2}\right)$ from gas cooking have been extensively studied in other countries. ${ }^{8.9}$ Our study was performed in a region where no gas cooking or gas heating was used. This made it possible to perform a study on respiratory effects of VOCs, which was not confounded by the emission of both VOCs and $\mathrm{NO}_{2}$ from gas combustion. Unfortunately, we did not measure indoor $\mathrm{NO}_{2}$ in our study. As possible sources of indoor $\mathrm{NO}_{2}$ in our study would have been traffic exhaust gases and indoor tobacco smoking, we expected the indoor concentrations of $\mathrm{NO}_{2}$ to be below the observed effect level of $30 \mu \mathrm{g} / \mathrm{m}^{3} \mathrm{NO}_{2} .{ }^{8}$ This assumption is supported by data from a recent study from mid-Sweden, where indoor concentrations of $\mathrm{NO}_{2}$ were between 4 and 18 $\mu \mathrm{g} / \mathrm{m}^{3}$ in urban dwellings and $1-10 \mu \mathrm{g} / \mathrm{m}^{3}$ in rural dwellings. ${ }^{33}$

We found significant relations between measured indoor concentrations of various VOCs in dwellings and symptoms related to asthma. To our knowledge, relations between asthmatic symptoms and measured VOCs have not been reported earlier in any epidemiological study. There are, however, some earlier studies that support the hypothesis that asthmatic symptoms may be related to indoor VOCs. In one population study, presence of newly painted surfaces indoors was related to asthmatic symptoms. ${ }^{34}$ Also, two experimental studies have shown that even moderate concentrations of VOCs may cause inflammation and obstructive reactions in the airways. ${ }^{35}{ }^{36} \mathrm{In}$ one study, it was shown that a four hour exposure of humans to $25 \mathrm{mg} / \mathrm{m}^{3}$ of a mixture of VOCs induced an inflammatory response in the nose, as shown by a significant increase of granulocytes in nasal lavage. ${ }^{35}$ In the other study, the same mixture of VOCs, caused a decline of $\mathrm{FEV}_{1}$ among asthmatic subjects after a 1.5 hour exposure to $25 \mathrm{mg} / \mathrm{m}^{3}$ of VOCs. ${ }^{36}$ To our knowledge, no exposure chamber studies of the effect on health related to asthma of VOCs below $25 \mathrm{mg} / \mathrm{m}^{3}$ are available. The average exposure in our study was well below $25 \mathrm{mg} / \mathrm{m}^{3}$, but a maximum concentration of $9 \mathrm{mg} / \mathrm{m}^{3}$ was measured in the bedroom of one symptomatic subject. Moreover, the exposure time is much longer in dwellings than in exposure chamber studies, and the types of VOCs in our dwellings differed from the mixture of VOCs used in studies mentioned above. Thus we do not consider it unlikely that the concentrations of VOCs measured in our study may contribute to asthmatic symptoms in some sensitive subjects.

Our findings that indoor concentrations of formaldehyde are related to asthmatic symptoms agree with another study that suggests that dwellings with more than $30 \mu \mathrm{g} / \mathrm{m}^{3}$ of formaldehyde had a higher proportion of children ( $<15$ years) with abnormal variability in PEF. ${ }^{37}$ Because of covariation between formaldehyde and VOCs, we were not able to separate the effect of these volatile compounds in our statistical analysis. Terpenes, however, were the only volatile compounds 
significantly related to both symptoms and clinical signs, including variability in PEF and bronchial hyperresponsiveness. We admit that it would have been better if we had measured peak flow four times a day, and a more frequent measurement of PEF may have increased the likelihood of detection of further health effects of indoor VOCs. Terpenes are usually considered to be harmless natural products, emitted from wood, paint, food, cleaners, and other consumer products. A maximum indoor concentration of $1.0 \mathrm{mg} / \mathrm{m}^{3}$ of terpenes was measured in our study, about two thirds being limonene. No activities known to emit terpenes, such as cleaning, or peeling of citrus fruits, were found that could explain the high values. Obstructive airway reactions to terpenes have earlier been shown at higher concentrations in sawmills. ${ }^{38}$ Our investigation, however, suggests that some sensitive subjects may show bronchial obstructive reactions at low exposures to terpenes in the indoor environment.

To improve management of asthma, and to counteract the increase in asthma, the importance of the indoor environment should not be neglected. Our results suggest that indoor exposure to VOCs may affect the airways and cause asthmatic symptoms. Improved indoor environment can be achieved by various means-for example, selecting building material, building construction, and indoor activities on the principle that the emission of VOCs should be as low as reasonably achievable. There is also a need to increase the outdoor air supply in many dwellings in Sweden. Finally, wall to wall carpeting, which could act as a depot for various types of pollutants, and dampness in the building should also be avoided.

This study was supported by grants from the Swedish Association against Asthma and Allergy, The Swedish Medical Research Council, The Swedish Society of Medicine, The Swedish Heart and Lung Foundation, The Bror Hjerpstedts Foundation, Pharmacia and the County Council of Uppsala.

1 Samet JM, Marbury MC, Spengler JD. Health effects of indoor air pollution. Part II. Am Rev Respir Dis 1989 137:221-42.

2 Samet J. Environmental controls and lung disease. Am Rev Respir Dis 1990;142:915-39.

3 Boman G. Epidemiology of obstructive lung diseases in the Nordic countries. European Respiratory Reviews 1991;

4 Åberg N. Asthma and allergic rhinitis in Swedish conscripts. Clin Exp Allergy 1989;19:59-63.

5 Burr ML, Butland BK, King S, Vaughan-Williams E. Changes in asthma prevalence: two surveys 15 years apart. Arch Dis Child 1989;64:1452-6.

6 Sears MR. Epidemiological trends in bronchial asthma. In Kaliner MA, Barnes PJ, Persson CG, eds. Asthma. It pathology and treatment. New York, Dekker, 1991:1-50.

7 Moschandreas DJ. Exposure to pollutants and daily time budgets of people. Bull NY Acad Med 1981;57:845-59.

8 Hasselblad V, Eddy DM, Kotchmar DJ. Synthesis of environmental evidence: nitrogen dioxide epidemiology
studies. $\mathcal{F}$ Air Waste Manage Assoc 1992;42:662-71.

9 Viegi G, Paoletti P, Carrozzi L, Vellutini M, Ballerin L, Biavati $\mathrm{P}$, et al. Effects of home environment on respiratory symptoms and lung function in a general population tory symptoms and lung function in a general pop

10 Burge PS, Richardson MN. Occupational asthma due to indirect exposure to lauryl dimethyl nenzyl ammonium indirect exposure to lauryl dimethyl nenzyl ammonium

11 Waegemaekers $M$, Van Wageningen N, Brunekreef $B$, Bolsei JSM. Respiratory symptoms in damp houses. Allergy 1989;44:192-8.

12 Platt SD, Martin CJ, Hunt SM, Lewis CW. Damp housing, mould growth and symptomatic health state. $B M \mathcal{F}$ 1989;298:1673-8.
13 Wickman M, Nordvall SL, Pershagen G, Sundell J, Schwartz B. House dust mite sensitization in children and residential characteristics in a temperate region. f Allergy Clin Immunol 1991;88:89-95.

14 Burge PS, Finnegan MJ, Horsfield N, Pickering CAC Occupational asthma in a factory with a contaminated humidifier. Thorax 1985;40:248-54.

15 Norbäck D, Edling C, Wieslander G, Ramadhan S. Exposure to volatile organic compounds (VOC) in the general Swedish population and its relation to perceived indoor air quality and sick building syndrome. In: of indoor air '93 vol 1, fuly 1993, Helsinki. Helsinki, of indoor air '93 vol 1, Fuly 1993, Helsinki. Helsinki, Finland: Laboratory of Heating, Ventilation and Air 573-8.

16 Sporik R, Holgate ST, Platts-Mills TEA, Cogswell J. Exposure to house-dust mite allergen (der $\mathrm{p} I$ ) and the development of asthma in childhood. $N$ Engl $\mathcal{F} \mathrm{Med}$ 1990;323:502-7.

17 Burney PGJ, Luczynska CM, Chinn S, Jarvis D. The European Community respiratory health survey. Eur Respir f 1994;7:954-60.

18 Andersson $\mathrm{K}$, Hallgren $\mathrm{C}$, Levin J-O, Nilsson C-A. Chemosorbtion sampling and analysis of formaldehyde in air: influence of recovery during the simultaneous sampling of formaldehyde, phenol, furfural, and furfuryl sampling of formaldehyde, phenol, furfural, and furfuryl

19 Norbäck D, Torgen M, Edling C. Volatile organic compounds, respirable dust, and personal factors related to prevalence and incidence of sick building syndrome in primary schools. Br F Ind Med 1990;47:733-41.

20 Van der Brempt X, Haddi E, Michel-Nguyen A, Fayon JP Soler $\mathrm{M}$, Charpin $\mathrm{D}$, et al. A comparison of the ACAREX test with monoclonal antibodies for the quantification of mite allergens. $\mathcal{F}$ Allergy Clin Immunol 1991; 87:130-2.

21 Chapman MD. Guanine - an adequate index of mite exposure? Allergy 1993;48:301-2.

22 Burney PGJ, Chinn S. Developing a new questionnaire for measuring the prevalence and distribution of asthma. Chest 1987;19(suppl):79-92.

23 Burney PGJ, Laitinen LA, Perdrizet, et al. Validity and repeatability of the IUATLD (1984) bronchial symptoms questionnaire: an international comparison. Eur Respir $\mathcal{f} 1989 ; 2: 940-5$

24 Dreborn S. Skin tests used for epidemiological studies. Allergy 1989;44(suppl):52-9.

25 European Community for Coal and Steel. Standardization of lung function tests. Clinical Respiratory Physiology 1983;19(suppl 5):22-7.

26 Higgins BG, Britton JR, Chinn S, Jones TD, Jenkinson D, Burney PG, Tattersfield AE. The distribution of peak expiratory flow variability in a population sample. $A m$ expiratory flow variability in a popu
Rev Respir Dis $1989 ; 140: 1368-72$.

27 Higgins BG, Britton JR, Chinn S, Cooper S, Burney PGJ, Tattersfield AE. Comparison of bronchial reactivity and peak expiratory flow variability measurements for epidemiological studies. Am Rev Respir Dis 1992;145: 588-93.

28 Knox AJ, Wisniewski A, Cooper S, Tattersfield AE. A comparison of the Yan and a dosimeter method for methacholin challenge in experienced and inexperienced subjects. Eur Respir $\mathcal{F} 1991 ; 4: 497-502$.

29 Peterson CGB, Enander I, Nystrand J, Andersson AS Nilson L, Venge P. Radioimmunoassay of human eosinophilic cationic protein (ECP) by an improved eosinophilic cationic protein (ECP) by an improved method. Establishment of normal levels in serum

30 Gebski V, Leung O, McNeil D, Lunn D. SPIDA user manual, version 6. Eastwood, Australia: Statistical Computing Laboratory, 1992.

31 ASHRAE. ASHRAE standard 62-89. Ventilation for acceptable indoor air quality. Atlanta: American Society of Heating, Refrigeration, and Airconditioning. Engineers Inc Atlanta, 1989.

32 National Swedish Board of Occupational Safety and Health. Ventilation and quality of air, AFS 1993;5. Stockholm: NSBOSH 1993. (In Swedish.)

33 Berglund M, Bråbäck L, Bylin G, Jonson J-O, Vather $M$ Personal $\mathrm{NO}_{2}$ exposure monitoring shows high exposure Personal $\mathrm{NO}_{2}$ exposure monitoring shows high exposure among ice-skating

34 Norbäck D, Edling C, Wieslander G. Asthma symptoms and the sick building syndrome (SBS) - the significance of microorganisms in the indoor environment. In Samson RA, Flannigan B, Flannigan ME, Verhoeff AP Adan OCG, Hoekstra ES, eds. Health implications of fungi in indoor environments. Air quality monographs, vol 2 . Amsterdam: Elsevier, 1994:229-39.

35 Koren HS, Graham DE, Devlin RB. Exposure of humans to volatile organic mixture III Inflammatory response. Arch Environ Health 1992;47:39-44.

36 Harving H, Dahl R, Mölhave L. Lung function and bronchial reactivity in asthmatics during exposure to volatile organic compounds. Am Rev Respir Dis 1991; volatile organ $1451-4$.

37 Quackenboss JJ, Lebowitz MD, Michaud JP, Bronniman Quackenboss JJ, Lebowitz MD, Michaud JP, Bronniman D. Formaldehyde exposure and acute health effec

38 Johard U. The wood trimmer's lung. Clinical and experimental studies focusing on inflammatory reactions. Stockholm: Unit of Lung Medicine, Institution of Medicine, Karolinska Hospital, Karolinska Institute, 1994. (Thesis.) 